\title{
Effectiveness and tolerability of a squalane and dimethicone-based treatment for head lice
}

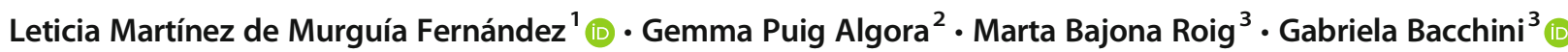

Received: 18 January 2021 / Accepted: 28 February 2021 / Published online: 2 April 2021

(C) The Author(s) 2021

\begin{abstract}
Head lice (Pediculus humanus capitis) are worldwide obligate human ectoparasites, with high implications in pediatrics. In Europe, first-line topical neurotoxic insecticidal therapeutic strategies are being replaced by topical physically acting agents as the first-choice treatment. Safety of the active ingredients and high efficacy in a one-time single-dose treatment with a brief treatment application time are key issues for consumer use and effective compliance. The aim of this study was to assess the in vitro efficacy of a newly developed squalane and dimethicone-based pediculicidal formula, against motile head lice and eggs after 2 and 5 min immersion in the product, as well as its skin tolerance and acceptability under dermatological and pediatric expert control in children with atopic skin. The results indicate that at both time points, $100 \%$ mortality rate of head lice crawling stages and latestage eggs was achieved. The formula was well tolerated and suitable for children with atopic skin from 12 months of age. Showing high in vitro efficacy and good skin acceptability, this solution is presented as a new safe alternative therapy for treatment of head lice infestations.
\end{abstract}

Keywords Head lice $\cdot$ Pediculicides $\cdot$ Physically acting $\cdot$ Ovicidal $\cdot$ In vitro efficacy $\cdot$ Children

\section{Introduction}

Head louse pediculosis due to Pediculus humanus capitis De Geer, 1778 is an endemic human ectoparasitic disease worldwide (Falagas et al. 2008). With variable infestation rates among regions and countries, it is considered a public health and social problem (Coates et al. 2020; Falagas et al. 2008; Feldmeier 2012) with economic implications (Hansen and O'Haver 2004; West 2004). Although all ages and diverse socioeconomic backgrounds are affected, it is particularly frequent among school children aged 4 to 12 years and other vulnerable groups such as the homeless, orphans, geriatrics,

Handling Editor: Una Ryan

Gabriela Bacchini

GBacchini@ferrer.com

1 TECNALIA, Basque Research and Technology Alliance (BRTA), Área Anardi, 5, E-20730 Azpeitia, Gipuzkoa, Spain

2 Ferrer, Cosmetic Development, C/Joan XXIII, 10, E-08950 Esplugues de Llobregat, Spain

3 Ferrer, Corporate Medical Affairs Department, Av. Diagonal 549, E-08029 Barcelona, Spain and refugees (Dietrich et al. 2018; Meister and Ochsendorf 2016; Tytuła et al. 2019). Pruritus, scalp irritation with potential secondary bacterial infections (Chosidow 2000) and social and psychological distress (Gordon 2007) are the main clinical manifestations. Unlike body lice, and despite identification on head lice of human pathogens including trench and relapsing fever bacteria, they are not known to transmit infectious diseases (Amanzougaghene et al. 2020).

Different head louse treatments based on diverse mechanisms of action are currently available (Sangaré et al. 2016). However, traditional topical neurotoxic insecticides are under review; some active ingredients have been banned based on safety concerns, while others have lost efficacy due to increasing resistance of head louse populations in different countries (Clark et al. 2015; Durand et al. 2012; Gellatly et al. 2016). As a result, new active ingredients and different treatment approaches are being developed around the world (Burgess 2016). In Europe, although safe formulations of insecticides (pyrethrins and pyrethroids) remain as first-line therapy, physically acting treatments are now gaining ground as the first-choice treatment (Burgess 2018, Burgess 2016; Feldmeier 2014; Meister and Ochsendorf 2016). Among these, several different products based on silicones, fixed and mineral oils, lipid esters, surfactants, or oilsurfactant copolymers have been commercialized (Burgess 
2018; Burgess 2016). Nevertheless, not all active ingredients and formulations show ovicidal activity, and a second or third treatment at 7- to 10-day intervals is often required to prevent emerging nymphs from establishing a new infestation (Barker et al. 2012; Lebwohl et al. 2007). For users, low compliance with this treatment strategy leads to treatment failure (Meister and Ochsendorf 2016). Thus, the development of new alternative products that target eggs and motile stages simultaneously, to treat head louse infestations in a single-dose treatment, is strongly encouraged (Barker et al. 2012).

In this context, a new innovative physically acting product was developed to be used in one single dose. The aim of the studies presented here was to evaluate the in vitro adulticidal and ovicidal efficacy of a new squalene and dimethicone-based product in different short immersion exposures and to assess its skin tolerance and acceptability under dermatological and pediatric expert control in children with atopic skin.

\section{Material and methods}

\section{Head lice and ethics}

Head lice were collected from the heads of volunteers by specialized personnel. Volunteers had not been treated with anti-louse products for 4 weeks before specimen collection. Fine-tooth lice combs were used for nymphs and adult lice collection, and only those eggs grey in color and less than $1 \mathrm{~cm}$ from the scalp were obtained by cutting the hair shaft at the base with round-pointed scissors. Volunteers gave written informed consent following the protocol approved by the Clinical Research Ethics Committee of the Hospital of Donostia (Gipuzkoa, Spain).

\section{Products}

Studies were conducted with the ready-to-use product "OTC ANTIPIOJOS FORMULA TOTAL," provided by Ferrer International S.A. (Spain). It is formulated with squalane, dimethicone, and lauryl alcohol. The formula contains a mix of low viscosity, volatile dimethicone, and medium viscosity dimethicone together with a $4 \%$ of high viscosity dimethicone. Squalane used in this formula is found in high concentration, and it comes entirely from bio-based feedstock: plant sugars, such as sugarcane. References "Ref. 72.1" and "Ref. 72.4" are two replicates of this final formulation, used to conduct the in vitro efficacy studies. The clinical study to assess skin tolerance was conducted with "Ref. 72.4."

\section{In vitro efficacy testing}

Both motile or crawling head lice and eggs were used. Product samples were conditioned at the same environmental conditions as the treatment application: $25 \pm 2{ }^{\circ} \mathrm{C}$ and $60 \pm$ $10 \%$ relative humidity $(\mathrm{RH})$. Treatments were carried out in $10 \mathrm{ml}$ of product poured into 5 -cm diameter Petri dishes following an in vitro immersion methodology (Mougabure Cueto et al. 2000), by submerging each group of specimens in the product. Specimens were then transferred to a permeable well, rinsed with tap water for $1 \mathrm{~min}$., and settled in 5-cm Petri dishes, previously labeled and lined with moistened filter paper (Whatman no. 1). Tap water was used in the negative controls, which were similarly conditioned. All experiments were done in triplicate.

Groups of 10 specimens of motile stages (3rd nymphal instar and adults of both sexes) were treated between 3 and $5 \mathrm{~h}$ after collection by immersion in the product for $2 \mathrm{~min}$ and incubated in the dark at $25 \pm 2{ }^{\circ} \mathrm{C}$ and $60 \pm 10 \%$ RH until time point observations. Vital signs were evaluated at $5,15,30,60$, and $180 \mathrm{~min}$ and $18 \mathrm{~h}$ post-product application under a stereoscopic microscope (Olympus SZ61TR with zoom up to $4.5 \times$ 20 magnifications) and following strictly defined criteria for vitality (Table 1). Mortality is the result of the combination of knocked down (vital signs reduced [VSR]) and dead (D) lice.

Hair shafts with eggs were inspected under the stereoscopic microscope and classified into early (no differentiation) and late (red or black eye spot and appendages and/or embryonic movements) stages, according to Sonnberg et al. (2010). Only late-stage eggs were used in this study. Groups of 10 specimens on hair shafts $(3 \mathrm{~cm})$ were treated by immersion at two different time exposures, 2 and $5 \mathrm{~min}$. They were then incubated in the dark at $29 \pm 1{ }^{\circ} \mathrm{C}$ and $>70 \% \mathrm{RH}$ until observation, at 7 days post-treatment, when all eggs in the controls had hatched. Defined criteria for viability are shown in Table 1 . Mortality is the result of the combination of incomplete hatching $(\mathrm{IH})$ and no hatching of late stages (LS).

\section{Statistical analysis}

The results from the replicates were pooled, and data was presented as the arithmetic mean percent adulticidal and ovicidal activity with their corresponding standard deviations ( \pm SD). The efficacy outcome was the mortality rate within each group of specimens considering both the number of alive and affected lice (VSR $+\mathrm{D}$ ) or completely hatched $(\mathrm{CH})$ and affected eggs $(\mathrm{IH}+\mathrm{LS})$ according to the equation (Number of affected lice or eggs/Total number of lice or eggs) $\times 100$. For final values, correction considering mortality in the controls was applied with the formula ([mortality $\%$ treatment $-\%$ mortality control $/ 100$ - $\%$ mortality control] $\times 100$ ). Statistical comparison of mortality relative frequencies in the treatments and controls were conducted using the Chi-squared test with the software package PAST (Hammer n.d., Version 4.02; Hammer et al. 2001). 
Table 1 Defined vitality criteria in motile lice and ova for product efficacy evaluation

Motile head lice vital signs' classification
(i) Alive
(ii) Vital signs apparent (VSA)
(iii) Vital signs reduced (VSR)
(iv) Dead (D)

Ova vital signs' classification

(i) Complete hatching $(\mathrm{CH})$

(ii) Incomplete hatching (IH)

(iii) No hatching of late stages (LS)

\section{Lice can walk, grab a hair, and move forward}

Lice movements are not coordinated, and they cannot walk or grab a hair and move forward

Lice show small movements in the antennae, legs, or digestive tract

Lice show complete cessation of movement, including the digestive tract

Eggs with the operculum opened and empty

Eggs with the operculum opened, but the nymph remains entirely or partially inside

Eggs with the operculum closed and dead embryo inside

Classification of motile head lice vital signs according to Oliveira et al. (2007)

\section{Clinical assessment of skin tolerance and acceptability under normal use conditions}

A clinical, prospective study was conducted to assess the absence of adverse reactions of discomfort and cumulative irritations (functional and physical signs) related to the application of the product in normal use conditions under dermatological and pediatric monitoring, as well as its acceptability, following the corresponding protocol and according to Good Clinical Practice guidelines in San Fermín Clinic (Pamplona, Spain). One pediatrician and one dermatologist assessed the clinical tolerance of the product by visual evaluation.

Children with atopic skin aged between 1 and 3 years, no flare-up in the last 4 weeks, were included after agreement and informed written consent by parents or guardians. The sample size was 20 evaluable children; this number being considered sufficient to assess the safety of the product by the investigators.

The parents/guardians of the children made three visits to the clinic in a 14-day period: day 0 , day 7 , and day 14 . On days 0 and 7, the pediculicide lotion was applied to the dry hair of the children under normal conditions of use, shown in
Table 2. At all visits, the researchers evaluated the area of application of the product to assess possible adverse reactions or irritation produced in the scalp, hair, and skin and especially in the eyes. Parents/guardians were also contacted by telephone within 3-4 days of application of the study product to confirm the absence of any adverse reactions. At the last visit, parents/ guardians were asked to complete a 4-point subjective product evaluation questionnaire to assess its organoleptic properties, where 0 is strongly disagree, 1 is disagree, 2 is agree, and 3 is strongly agree. The results were expressed as $\%$ of parents/ guardians satisfied with the product (score of 2 or 3 ).

\section{Results}

\section{Adulticidal efficacy}

Two-minute immersion treatment of crawling stages showed that at 5 min post-treatment, all lice were classified as nonviable, with only three lice showing few minor vital signs (gut movements) and the rest described as dead at this observation point (Table 3). Ten minutes later, all individuals were dead.

Table 2 Instructions for application of the product "OTC ANTIPIOJOS FORMULA TOTAL" under normal conditions of use

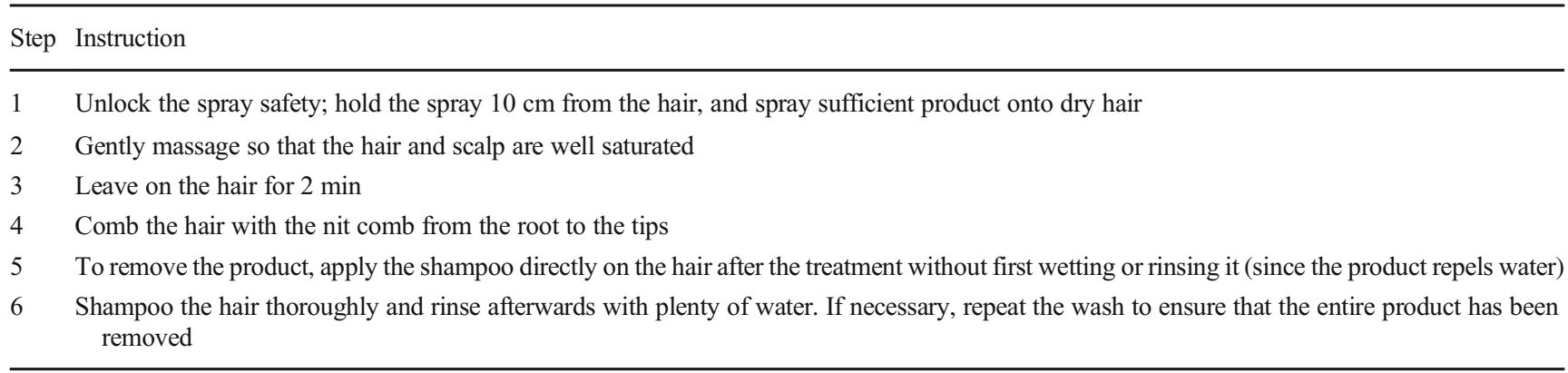


Table 3 Vital signs recorded for motile head lice

\begin{tabular}{|c|c|c|c|c|c|c|c|}
\hline \multirow[t]{3}{*}{ Treatment } & \multirow[t]{3}{*}{ Replicates } & \multicolumn{6}{|c|}{ Time treatment application: $2 \mathrm{~min}$} \\
\hline & & \multicolumn{6}{|c|}{ Time point observations after treatment application } \\
\hline & & $5 \mathrm{~min}$ & $15 \mathrm{~min}$ & $30 \min$ & $60 \mathrm{~min}$ & $180 \mathrm{~min}$ & $18 \mathrm{~h}$ \\
\hline \multirow[t]{2}{*}{ Control } & $3(n=30)$ & 0 & 0 & 0 & 0 & 0 & $14^{\mathrm{b}}$ \\
\hline & $\begin{array}{l}\text { Mortality (\%) } \\
\text { Mean } \pm \text { SD }\end{array}$ & $00 \pm 0$ & $00 \pm 0$ & $00 \pm 0$ & $00 \pm 0$ & $00 \pm 0$ & $47 \pm 6$ \\
\hline \multirow{2}{*}{$\begin{array}{l}\text { OTC ANTIPIOJOS FORMULA TOTAL } \\
\text { "Ref. } 72.1 "\end{array}$} & $3(\mathrm{n}=30)$ & $3^{\mathrm{a}} 27^{\mathrm{b}}$ & $30^{\mathrm{b}}$ & $30^{\mathrm{b}}$ & $30^{\mathrm{b}}$ & $30^{\mathrm{b}}$ & $30^{\mathrm{b}}$ \\
\hline & $\begin{array}{l}\text { Mortality }(\%) \\
\text { Mean } \pm \text { SD }\end{array}$ & $100 \pm 0$ & $100 \pm 0$ & $100 \pm 0$ & $100 \pm 0$ & $100 \pm 0$ & $100 \pm 0$ \\
\hline $\begin{array}{l}\text { Corrected mortality (\%) } \\
\text { Mean } \pm \text { SD }\end{array}$ & & $100 \pm 0$ & $100 \pm 0$ & $100 \pm 0$ & $100 \pm 0$ & $100 \pm 0$ & $100 \pm 0$ \\
\hline
\end{tabular}

${ }^{\mathrm{a}}$ VSR (vital signs reduced); ${ }^{\mathrm{b}} \mathrm{D}(\mathrm{dead})$

Raw data and mean percentage mortality (\%) and standard deviations (SD) for each observation time point and pooled replicates after the 2-min immersion treatment with "OTC ANTIPIOJOS FORMULA TOTAL"

Immobilization was observed in all individuals immediately after application, and gut rupture was observed at different time points. Results were similar in all three replicates and were pooled, giving a final mean mortality of $100 \pm 0 \%$ at all time point observations, as compared with control lice that were all alive $3 \mathrm{~h}$ after treatment with water. The mean percentage mortality observed in the negative controls at $18 \mathrm{~h}$ (47\%) was due to dehydration of the lice when they are outside the host. Mortality with the product was statistically significant from the water controls, at both endpoints, $3 \mathrm{~h}\left(\mathrm{Chi}^{2}=\right.$ 60 , d.f. $1, P<0.001)$ and $18 \mathrm{~h}\left(\mathrm{Chi}^{2}=21.818\right.$, d.f. $1, P<$ $0.001)$.

\section{Ovicidal efficacy}

Both the 2- and 5-min immersion treatments with late-stage eggs showed similar results in all replicates and were pooled, being $100 \%$ the mean mortality value as no louse hatched after 7 days and hatching in the negative controls gave $83.3 \%$ survival, respectively (Table 4). Corrected mortality values confirm a mean of $100 \%$ efficacy in both treatment regimes. When comparing between the product and control, differences were statistically significant in the two-time experiments $\left(\mathrm{Chi}^{2}\right.$ $=42.857$, d.f. $1, P<0.001)$. All eggs died within the stage they were treated, red or black eyespot, with no incomplete hatching or dead emerging nymph observed in any of the treated replicates. Observations made immediately after the 2-min treatment showed that periodic pumping movements of the pharynx and gut movements had ceased in several eggs but continued to be observed in other specimens. As we did not record this data, we do not know the exact moment when the embryos died.

\section{Clinical assessment of skin tolerance and acceptability under normal use conditions}

A total of 10 boys and 10 girls were included in the study, from 12 to 34 months old. The product did not produce any undesirable skin reactions in the study participants after 14 days of use, according to the study researchers (dermatologist and pediatrician). During the 14-day study period, none of the parents or guardians reported any undesirable reactions. Overall, $100 \%$ of parents or guardians said that they were satisfied with the properties of the product, including odor, texture, quick and easy application, absence of skin and eye irritation, or redness.

\section{Discussion}

Physically acting pediculicides are a safe and effective alternative to traditional insecticides for treating head louse infestations (Burgess 2018; Burgess 2016; Clark et al. 2013; Feldmeier 2014; Flores-Genuino et al. 2020). A one-time single-dose treatment that simultaneously targets motile head lice and eggs on the scalp is easier to use and aims to increase cure rates (Abdel-Ghaffar et al. 2012; Barker et al. 2012; Burgess and Burgess 2011; Heukelbach et al. 2011; Semmler et al. 2017). Furthermore, efficacy with a short application time ( $5 \mathrm{~min}$ or less) is considered to fulfill the requirements of a first-choice pediculicide, which, in addition, should also avoid louse resistance development and be safe for both host and environment (Abdel-Ghaffar et al. 2010; Gordon 2007).

The specific composition of "OTC ANTIPIOJOS FORMULA TOTAL" is included in an International 
Table 4 Vital signs recorded for head lice late-stage eggs

\begin{tabular}{|c|c|c|c|c|c|c|c|}
\hline \multirow[t]{3}{*}{ Treatment } & \multirow[t]{3}{*}{ Replicates } & \multicolumn{6}{|c|}{ Reference and time treatment application } \\
\hline & & \multicolumn{3}{|c|}{ Ref. $72.1: 5 \mathrm{~min}$} & \multicolumn{3}{|c|}{ Ref. 72.4: $2 \mathrm{~min}$} \\
\hline & & $\mathrm{LS}^{\mathrm{c}}$ & $\mathrm{IH}^{\mathrm{d}}$ & $\mathrm{CH}^{\mathrm{e}}$ & $\mathrm{LS}^{\mathrm{c}}$ & $\mathrm{IH}^{\mathrm{d}}$ & $\mathrm{CH}^{\mathrm{e}}$ \\
\hline \multirow[t]{2}{*}{ Control } & $3(n=30)$ & 5 & 0 & 25 & 5 & 0 & 25 \\
\hline & Mean \pm SD $(\%)$ & $16.67 \pm 5.77$ & $00 \pm 0.00$ & $83.33 \pm 5.77$ & $16.67 \pm 5.77$ & $00 \pm 0.00$ & $83.33 \pm 5.77$ \\
\hline \multirow[t]{2}{*}{ OTC ANTIPIOJOS FORMULA TOTAL } & $3(n=30)$ & 30 & 0 & 0 & 30 & 0 & 0 \\
\hline & Mean $\pm \mathrm{SD}(\%)$ & $100 \pm 0.00$ & $00 \pm 0.00$ & $00 \pm 0.00$ & $100 \pm 0.00$ & $00 \pm 0.00$ & $00 \pm 0.00$ \\
\hline $\begin{array}{l}\text { Corrected mortality } \\
\text { Mean } \pm \text { SD }(\%)\end{array}$ & & $100 \pm 0.00$ & $00 \pm 0.00$ & - & $100 \pm 0.00$ & $00 \pm 0.00$ & - \\
\hline
\end{tabular}

${ }^{\mathrm{c}} L S$ no hatching of late stage, ${ }^{\mathrm{d}} \mathrm{IH}$ incomplete hatching, ${ }^{\mathrm{e}} \mathrm{CH}$ complete hatching

Raw data and mean percentage mortality (\%) in late stages (LS) and incomplete hatching (IH) categories, along with survival data (CH), with their standard deviations (SD) for pooled replicates and treatment exposure time (5 and $2 \mathrm{~min}$ ) at 7 days post-product application with "OTC ANTIPIOJOS FORMULA TOTAL." Survival in the controls corresponds to the mean natural egg hatching rate, reported to be $76 \%$ by Takano-Lee et al. (2003)

Application published under the Patent Cooperation Treaty (PCT), International Publication Number WO 2019/008116 (Bacchini and Puig Algora 2018). Squalane, a saturated aliphatic hydrocarbon, is obtained by the hydrogenation of squalene, which is contained in shark liver oil, rice, olives, or soybean (Popa et al. 2014). Squalane used in this formula is a product of fermentation and comes entirely from bio-based feedstock. It is certified as $100 \%$ bio-based (United States Department of Agriculture n.d.) and conforms to ECOCERT's natural cosmetic standard (Ecocert Group n.d.). It adheres to the International Standard ISO 16128-1 (International Organization for Standardization n.d.-a) and has a natural origin index of 1.00 per ISO 16128-2 (International Organization for Standardization n.d.-b). Squalane has low toxicity and is frequently used in cosmetics as an emollient and moisturizer (Kelly 1999; Popa et al. 2014). Indeed, squalane emulsions have been proposed as viable alternative formulations in efficient vaccine delivery systems (Kantipakala et al. 2019; Kelly 1999). Dimethicone, a clear and odorless polydimethylsiloxane (PDMS) fluid with different molecular weights, is widely used in cosmetics, with a good safety profile (Becker et al. 2014), and in pharmaceutical products including head louse treatments (Colas et al. 2005). They are applied in the same way as other lotions for head louse infestation, by coating the scalp and full length of the hair (Burgess et al. 2005). They seem less irritant than existing pediculicidal treatments and have a physical action on lice that should not be affected by resistance to neurotoxic insecticides (Burgess 2018). Lauryl alcohol (1-dodecanol), a fatty alcohol produced from palm kernel oil or coconut oil and widely used as a liquid emulsifier and emollient for cosmetics formulations, is a desirable component in pediculicidal hair lotions for its effects on both motile lice (Mougabure Cueto et al. 2002) and eggs (Heukelbach et al.
2007). Previous studies on the mechanism of action with an initial formulation containing squalane, cyclopentasiloxane - a volatile silicone - and ethylhexyl stearate were performed (Bacchini and Puig Algora 2018; Bajona Roig et al. 2019a). They indicated that the squalane-based formula, without dimethicone, was able to penetrate through the cuticle of the lice exoskeleton and into the respiratory tract of motile stages (staining of spiracles, trachea, and tracheoles) and aeropyles of the operculum of late eggs (inner membranes surrounding the embryo were stained). Moreover, after $60-90 \mathrm{~s}$ of lice immersion in the formulation, any apparent movement stops besides peristaltic movements of the intestine, without subsequent signs of recovery. These findings, along with gut rupture in motile stages, are similar to those described for a physical mode of action of silicone-based products: disruption of the integrity of the lipid cuticle of the louse exoskeleton leading to dehydration and death (Barnett et al. 2012) and occlusion of the respiratory system causing death by osmotic stress due to inhibition of water excretion (Burgess 2009). Anoxia or suffocation, as the mode of action, is controversial (Burgess 2018). With respect to eggs, it has been suggested that effective compositions could act by blocking the micropyles of the inner membranes, interfering in the respiratory processes by limiting the oxygen supply or favoring carbon dioxide accumulation, leading in both cases to death of the embryo (Heukelbach et al. 2011; Mehlhorn et al. 2011).

The direct immersion methodology applied for the efficacy studies is considered a sensitive method to detect small differences in mortality between formulations (Gallardo et al. 2012). This claim is in line with the results obtained with different initial squalane-based formulations-without dimethicone - previously tested (Bacchini and Puig Algora 2018; Bajona Roig et al. 2018). Efficacy against crawling stages was consistently as high as $100 \%$ at different 
immersion times. However, the mean ovicidal mortality ranged from 27 to $93 \%$, depending on the immersion time (2 to $12 \mathrm{~min}$, respectively).

The final formulation used in this in vitro efficacy study has shown $100 \%$ adulticidal and ovicidal effectiveness. It contains a mix of low, medium, and high viscosity dimethicones, the latter in $4 \%$ concentration that has been shown to be effective in physical acting head louse treatments (Burgess et al. 2005). This carefully designed combination of dimethicones of different molecular weights together with high concentration of squalane and a small amount of lauryl alcohol improves its mortality potency and confers good cosmeticity. Its good efficacy is similar to the data reported in other studies of different silicone-based commercial pediculicides (Gallardo et al. 2012; Heukelbach et al. 2019). Furthermore, the formulation shows full efficacy in only $2 \mathrm{~min}$, following the global tendency to reduce the application time in order to increase treatment compliance. Other in vitro studies of physical acting agents confirm that motile head lice and eggs can be killed within a few minutes, although not all formulations achieve $100 \%$ ovicidal activity (Abdel-Ghaffar et al. 2012; AbdelGhaffar et al. 2010; Gallardo et al. 2012; Heukelbach et al. 2019; Mehlhorn et al. 2011; Oliveira et al. 2007; Strycharz et al. 2012).

Good skin compatibility, even for use in young children with atopic skin, was obtained with the final formulation. These results are in line with previously reported data with the initial squalene-based formulation (Bacchini and Puig Algora 2018; Bajona Roig et al. 2019b). It offers the highly desirable combination of being effective, spreading evenly, drying quickly, and being hair and skin compatible by not having a greasy or oily texture. Therefore, it eliminates the disadvantages of previously available compositions, namely, being difficult and unpleasant to apply, emitting a nasty odor, having limited effectiveness, and having substantial mammalian toxicity or tolerability issues.

Thus, according to the studies, this new squalene and dimethicone-based pediculicide complies with the main characteristics to become an effective alternative therapy in one single and brief application dose for children from 12 months of age, with good skin compatibility and acceptability.

Supplementary Information The online version contains supplementary material available at https://doi.org/10.1007/s00436-021-07113-y.

Acknowledgements The authors thank Lidia Merino for assistance in collecting the head lice and Alberto de Castro for statistical advice. The medical writers of Medical Statistics Consulting (Valencia) assisted in the preparation of the manuscript, which was critically reviewed by the authors until final approval.

Funding This work was funded by Ferrer International S.A., the company that developed the human head louse treatment discussed in this paper. This solution is marketed as "OTC ANTIPIOJOS FORMULA TOTAL" by Ferrer International S.A. in Spain.

\section{Declarations}

Ethics approval Head lice collection for the in vitro study followed the protocol approved by the Clinical Research Ethics Committee of the Hospital of Donostia (Gipuzkoa, Spain) and was performed in accordance with the ethical standards of Declaration of Helsinki. Clinical use test followed the corresponding protocol according to Good Clinical Practice guidelines in San Fermín Clinic (Pamplona, Spain) and was performed in accordance with the ethical standards of Declaration of Helsinki.

Consent to participate Written informed consent was obtained from all individual participants included in the studies or from parents or legal guardians when applicable.

Conflict of interest L. Martínez de Murguía Fernández is a scientific consultant of Ferrer International S.A. The company has not participated in the protocol design, performance, or interpretation of the laboratory and clinical studies. Neither the principal author nor Tecnalia has commercial interests in the tested product. G. Bacchini, G. Puig Algora, and M. Bajona Roig are employees of Ferrer International S.A.

Open Access This article is licensed under a Creative Commons Attribution 4.0 International License, which permits use, sharing, adaptation, distribution and reproduction in any medium or format, as long as you give appropriate credit to the original author(s) and the source, provide a link to the Creative Commons licence, and indicate if changes were made. The images or other third party material in this article are included in the article's Creative Commons licence, unless indicated otherwise in a credit line to the material. If material is not included in the article's Creative Commons licence and your intended use is not permitted by statutory regulation or exceeds the permitted use, you will need to obtain permission directly from the copyright holder. To view a copy of this licence, visit http://creativecommons.org/licenses/by/4.0/.

\section{References}

Abdel-Ghaffar F, Semmler M, Al-Rasheid K, Klimpel S, Mehlhorn H (2010) Comparative in vitro tests on the efficacy and safety of 13 anti-head-lice products. Parasitol Res 106:423-429. https://doi.org/ 10.1007/s00436-009-1680-x

Abdel-Ghaffar F, Al-Quraishy S, Al-Rasheid KAS, Mehlhorn H (2012) Efficacy of a single treatment of head lice with a neem seed extract: an in vivo and in vitro study on nits and motile stages. Parasitol Res 110:277-280. https://doi.org/10.1007/s00436-011-2484-3

Amanzougaghene N, Fenollar F, Raoult D, Mediannikov O (2020) Where are we with human lice? A review of the current state of knowledge. Front Cell Infect Microbiol 9. https://doi.org/10.3389/ fcimb.2019.00474

Bacchini GS, Puig Algora G (2018) inventors; Ferrer International SA, assignee. Compounds, compositions thereof and methods for treating ectoparasite infestation. World patent application WO 2019/008116

Bajona Roig M, Bacchini GS, Puig Algora G 2018. Pediculicidal efficacy of two products against Pediculus humanus capitis adults, nymphs and nits. Poster 48. Presented at the 30th Meeting of the Spanish Group of Aesthetic and Therapeutic Dermatology of the Spanish Academy of Dermatology and Venereology (GEDET), San Sebastian Spain

Bajona Roig M, Bacchini GS, Puig Algora G 2019a. Mechanism of action of a new pediculicide in motile forms (adults and late nymphs) and eggs (nits) of the head louse, Pediculus humanus 
capitis. Poster A66. Presented at the 31st INFARMA - European Meeting of Pharmacy, Barcelone Spain

Bajona Roig M, Bacchini GS, Puig Algora G 2019b. Evaluation of the compatibility and skin acceptability of a new pediculicide in atopic children from 6 months of age. Poster A65. Presented at the 31st INFARMA - European Meeting of Pharmacy, Barcelone Spain

Barker SC, Burgess I, Meinking TL, Mumcuoglu KY (2012) International guidelines for clinical trials with pediculicides. Int $\mathrm{J}$ Dermatol 51:853-858. https://doi.org/10.1111/j.1365-4632.2011. 05446.x

Barnett E, Palma KG, Clayton B, Ballard T (2012) Effectiveness of isopropyl myristate/cyclomethicone D5 solution of removing cuticular hydrocarbons from human head lice (Pediculus humanus capitis). BMC Dermatol 12:15. https://doi.org/10.1186/1471-5945-12-15

Becker LC, Bergfeld WF, Belsito DV, Hill RA, Klaassen CD, Liebler DC, Marks JG, Shank RC, Slaga TJ, Snyder PW, Andersen FA (2014) Safety assessment of dimethicone crosspolymers as used in cosmetics. Int J Toxicol 33:65S-115S. https://doi.org/10.1177/ 1091581814524963

Burgess IF (2009) The mode of action of dimeticone 4\% lotion against head lice. Pediculus capitis BMC Pharmacol 9:3. https://doi.org/10. 1186/1471-2210-9-3

Burgess IF, 2016. Current approaches to head louse treatment - a global update [WWW Document]. SelfCare J. URL https://selfcarejournal. com/article/current-approaches-head-louse-treatment-globalupdate/ (accessed 1.10.21)

Burgess IF 2018 Physically acting products for head lice - the end of the beginning (No. e27412v1). PeerJ Inc. doi:https://doi.org/10.7287/ peerj.preprints. $27412 \mathrm{v} 1$

Burgess IF, Burgess NA (2011) Dimeticone 4\% liquid gel found to kill all lice and eggs with a single 15 minute application. BMC Res Notes 4 : 15. https://doi.org/10.1186/1756-0500-4-15

Burgess IF, Brown CM, Lee PN (2005) Treatment of head louse infestation with $4 \%$ dimeticone lotion: randomised controlled equivalence trial. BMJ 330:1423. https://doi.org/10.1136/bmj.38497.506481.8F

Chosidow O (2000) Scabies and pediculosis. Lancet Lond Engl 355:819 826. https://doi.org/10.1016/s0140-6736(99)09458-1

Clark JM, Yoon KS, Lee SH, Pittendrigh BR (2013) Human lice: Past, present and future control. Pestic Biochem Physiol 106:162-171. https://doi.org/10.1016/j.pestbp.2013.03.008

Clark JM, Yoon KS, Kim JH, Lee SH, Pittendrigh BR (2015) Utilization of the human louse genome to study insecticide resistance and innate immune response. Pestic Biochem Physiol 120:125-132. https:// doi.org/10.1016/j.pestbp.2014.11.008

Coates SJ, Thomas C, Chosidow O, Engelman D, Chang AY (2020) Ectoparasites: pediculosis and tungiasis. J Am Acad Dermatol 82: 551-569. https://doi.org/10.1016/j.jaad.2019.05.110

Colas A, DowCorning SA, Rafidison P, (2005) Silicones in new pharmaceutical developments, from formulations to manufacturing processes [WWW Document]. URL /paper/Silicones-in-new-pharmaceutical-developments-\%2C-from-Colas-DowCorning/ b4dc093b3f348ace499f8b0b6762a09c2470babd (accessed 1.10.21)

Dietrich A, Joshi K, Sayed C (2018) Infestations in the Geriatric Patient. Curr Geriatr Rep 7:210-215. https://doi.org/10.1007/s13670-0180255-Z

Durand R, Bouvresse S, Berdjane Z, Izri A, Chosidow O, Clark JM (2012) Insecticide resistance in head lice: clinical, parasitological and genetic aspects. Clin Microbiol Infect Off Publ Eur Soc Clin Microbiol Infect Dis 18:338-344. https://doi.org/10.1111/j.14690691.2012.03806.x

Ecocert Group (n.d.) COSMOS certification (organic or natural cosmetics) | Ecocert [WWW Document]. URL https://www.ecocert. $\mathrm{com} / \mathrm{en} /$ certification-detail/natural-and-organic-cosmetics-cosmos (accessed 2.17.21)
Falagas ME, Matthaiou DK, Rafailidis PI, Panos G, Pappas G (2008) Worldwide prevalence of head lice. Emerg Infect Dis 14:14931494. https://doi.org/10.3201/eid1409.080368

Feldmeier H (2012) Pediculosis capitis: new insights into epidemiology, diagnosis and treatment. Eur J Clin Microbiol Infect Dis Off Publ Eur Soc Clin Microbiol 31:2105-2110. https://doi.org/10.1007/ s10096-012-1575-0

Feldmeier H (2014) Treatment of pediculosis capitis: a critical appraisal of the current literature. Am J Clin Dermatol 15:401-412. https:// doi.org/10.1007/s40257-014-0094-4

Flores-Genuino RNS, Gnilo CMS, Dofitas BL (2020) Occlusive versus neurotoxic agents for topical treatment of head lice infestation: A systematic review and meta-analysis. Pediatr Dermatol 37:86-92. https://doi.org/10.1111/pde.14016

Gallardo A, Mougabure-Cueto G, Vassena C, Picollo MI, Toloza AC (2012) Comparative efficacy of new commercial pediculicides against adults and eggs of Pediculus humanus capitis (head lice). Parasitol Res 110:1601-1606. https://doi.org/10.1007/s00436-0112668-x

Gellatly KJ, Krim S, Palenchar DJ, Shepherd K, Yoon KS, Rhodes CJ, Lee SH, Marshall Clark J (2016) Expansion of the knockdown resistance frequency map for human head lice (Phthiraptera: Pediculidae) in the United States using quantitative sequencing. J Med Entomol 53:653-659. https://doi.org/10.1093/jme/tjw023

Gordon SC (2007) Shared vulnerability: a theory of caring for children with persistent head lice. J Sch Nurs Off Publ Natl Assoc Sch Nurses 23:283-292. https://doi.org/10.1177/10598405070230050701

Hammer Ø (n.d.) PAST: PAleontological Statistics Version 4.02. 19992020. Reference Manual. Natural History Museum. University of Oslo [WWW Document]. URL http://priede.bf.lu.lv/ftp/pub/TIS/ datu analiize/PAST/4.xx/past-4.02-manual.pdf (accessed 1.10.21)

Hammer Ø, Harper D, Ryan P, 2001. PAST: Paleontological statistics software package for education and data analysis [WWW Document]. Palaeontol. Electron. URL https://palaeo-electronica. org/2001_1/past/issue1_01.htm (accessed 1.10.21).

Hansen RC, O'Haver J (2004) Economic considerations associated with Pediculus humanus capitis infestation. Clin Pediatr (Phila) 43:523527. https://doi.org/10.1177/000992280404300603

Heukelbach J, Canyon D, Speare R (2007) The effect of natural products on head lice: in vitro tests and clinical evidence. J Pediatr Infect Dis 2:67-76

Heukelbach J, Sonnberg S, Becher H, Melo I, Speare R, Oliveira FA (2011) Ovicidal efficacy of high concentration dimeticone: a new era of head lice treatment. J Am Acad Dermatol 64:e61-e62. https:// doi.org/10.1016/j.jaad.2010.04.003

Heukelbach J, Wolf D, Clark JM, Dautel H, Roeschmann K (2019) High efficacy of a dimeticone-based pediculicide following a brief application: in vitro assays and randomized controlled investigatorblinded clinical trial. BMC Dermatol 19:14. https://doi.org/10. 1186/s12895-019-0094-4

International Organization for Standardization (n.d.-a). ISO 16128-1: 2016(en), Guidelines on technical definitions and criteria for natural and organic cosmetic ingredients and products - Part 1: Definitions for ingredients [WWW Document]. URL https://www.iso.org/obp/ ui/\#iso:std:iso:16128:-1:ed-1:v1:en (accessed 2.17.21)

International Organization for Standardization (n.d.-b) ISO 16128-2: 2017(en), Cosmetics - guidelines on technical definitions and criteria for natural and organic cosmetic ingredients - Part 2: Criteria for ingredients and products [WWW Document]. URL https://www.iso.org/obp/ui/\#iso:std:iso:16128:-2:ed-1:v1:en (accessed 2.17.21)

Kantipakala R, Bonam SR, Vemireddy S, Miryala S, Halmuthur MSK (2019) Squalane-based emulsion vaccine delivery system: composition with murabutide activate Th1 response. Pharm Dev Technol 24:269-275. https://doi.org/10.1080/10837450.2018.1469150 
Kelly GS (1999) Squalene and its potential clinical uses. Altern Med Rev J Clin Ther 4:29-36

Lebwohl M, Clark L, Levitt J (2007) Therapy for head lice based on life cycle, resistance, and safety considerations. Pediatrics 119:965-974. https://doi.org/10.1542/peds.2006-3087

Mehlhorn H, Abdel-Ghaffar F, Al-Rasheid KAS, Schmidt J, Semmler M (2011) Ovicidal effects of a neem seed extract preparation on eggs of body and head lice. Parasitol Res 109:1299-1302. https://doi.org/ 10.1007/s00436-011-2374-8

Meister L, Ochsendorf F (2016) Head Lice Dtsch Arzteblatt Int 113:763772. https://doi.org/10.3238/arztebl.2016.0763

Mougabure Cueto G, Vassena C, González Audino P, Picollo M, Zerba E (2000) Efectividad de lociones capilares sobre poblaciones de Pediculus capitis resistentes a insecticidas. Acta Toxicol Argent 8: $10-12$

Mougabure Cueto G, Gonzalez Audino P, Vassena CV, Picollo MI, Zerba EN (2002) Toxic effect of aliphatic alcohols against susceptible and permethrin-resistant Pediculus humanus capitis (Anoplura: Pediculidae). J Med Entomol 39:457-460. https://doi.org/10.1603/ 0022-2585-39.3.457

Oliveira FAS, Speare R, Heukelbach J (2007) High in vitro efficacy of Nyda L, a pediculicide containing dimeticone. J Eur Acad Dermatol Venereol JEADV 21:1325-1329. https://doi.org/10.1111/j.14683083.2007.02258.x

Popa I, Băbeanu N, Niţă S, Popa O (2014) Squalene-natural resources and applications. Farmacia 62:840-862

Sangaré AK, Doumbo OK, Raoult D (2016) Management and treatment of human lice. Biomed Res Int 2016:8962685. https://doi.org/10. 1155/2016/8962685

Semmler M, Abdel-Ghaffar F, Gestmann F, Abdel-Aty M, Rizk I, AlQuraishy S, Lehmacher W, Hoff N-P (2017) Randomized, investigator-blinded, controlled clinical study with lice shampoo (Licener ${ }^{\circledR}$ ) versus dimethicone (Jacutin ${ }^{\circledR}$ Pedicul Fluid) for the treatment of infestations with head lice. Parasitol Res 116:18631870. https://doi.org/10.1007/s00436-017-5461-7

Sonnberg S, Oliveira F, Melo I, De M, Soares M, Becher H, Heukelbach J (2010) Ex Vivo Development of Eggs from Head Lice (Pediculus humanus capitis). Open Dermatol J 4:82-89. https://doi.org/10. 2174/1874372201004030082

Strycharz J, Lao A, Alves A, Clark J (2012) Ovicidal response of NYDA formulations on the human head louse (Anoplura: Pediculidae) using a hair tuft bioassay. J Med Entomol 49:336-342

Takano-Lee M, Yoon KS, Edman JD, Mullens BA, Clark JM (2003) In vivo and in vitro rearing of Pediculus humanus capitis (Anoplura: Pediculidae). J Med Entomol 40(5):628-635. https:// doi.org/10.1603/0022-2585-40.5.628

Tytuła A, Bartosik K, Jasztal-Kniażuk A, Buczek W, Błaszkiewicz A, Borzęcka-Sapko A (2019) Analysis of the prevalence of pediculosis and scabies in orphanages and refugee shelters in south-eastern Poland. J Educ Health Sport 9:493-500. https://doi.org/10.5281/ zenodo. 2605743

United States Department of Agriculture (n.d.). BioPreferred|Catalog [WWW Document]. BioPreferred® Program. URL https://www. biopreferred.gov/BioPreferred/faces/catalog/Catalog.xhtml (accessed 2.17.21)

West D (2004) Head lice treatment costs and the impact on managed care. Am J Manag Care 10:S277-S282

Publisher's Note Springer Nature remains neutral with regard to jurisdictional claims in published maps and institutional affiliations. 